\title{
Thyroid carcinoma in an autonomously hyperfunctioning thyroid nodule
}

\author{
O. KHAN \\ B.Sc., M.B., PhD. (Lond.), F.R.I.C. \\ P. J. ELL \\ M.D., MSc. \\ K. A. Maclennan \\ M.B. B.S. \\ A. KURTZ \\ Ph.D., M.B., M.R.C.P.
E. S. Williams
M.D., F.R.C.P. \\ Department of Nuclear Medicine and the Bland Sutton Institute, \\ The Middlesex Hospital Medical School, London WIN 8AA
}

\begin{abstract}
Summary
A 44-year-old woman presented with hyperthyroidism and a nodule in her thyroid. ${ }^{131}$ I-scintigraphy of the gland showed concentration of the tracer within the nodule and suppressed activity in the rest of the gland. Histology of the resected thyroid proved the nodule to be a papillary carcinoma. The presence of carcinoma within an autonomous hyperactive thyroid in a patient with hyperthyroidism has been reported only rarely, and to the authors' knowledge such a case has never been reported in Great Britain. Furthermore, unlike previously reported cases, the carcinoma was confined solely to the nodule.

\section{Introduction}

Thyroid carcinoma as a cause of thyrotoxicosis has been reported only rarely (Hunt, Crispell and McKee, 1960; Bloise et al., 1963). In nearly all of these cases, hyperthyroidism was due to hyperfunction in metastatic lesions. A search of the literature shows that there have been reported only 10 cases of a carcinoma being within an autonomously functioning thyroid nodule (Lamberg, McKinen and Murtom, 1976), and in the majority of these cases histological sections showed that the carcinoma involved other areas of the thyroid gland besides the nodule. As far as the present authors are aware, the presence of carcinoma within an autonomous hyperactive thyroid nodule in a patient with hyperthyroidism has not been reported in Great Britain, and furthermore, confinement of the carcinoma solely to the nodule has never been reported.
\end{abstract}

\section{Case history}

A 44-year-old female presented to her general practitioner in May 1978 complaining of heat intolerance, of intermittent episodes of passing loose $\bar{z}$ stools and of feeling generally unwell. In addition, she complained of a lump in the right side of her neck which recently had increased in size. She $\operatorname{was}_{\overrightarrow{0}}$ referred for a surgical opinion. Apart from mifdo hypertension, which was well controlled with thiazide diuretic, her previous medical history waso unremarkable. She had not lost any weight and her appetite was normal.

In April 1979, it was noted that she appeared $\stackrel{0}{\circ}$ anxious, her palms were sweaty, and she had a fine $\varrho$ tremor of the outstretched hands. Her sleeping pulse $\overrightarrow{\vec{O}}$ was $90 / \mathrm{min}$ and her BP was $150 / 90 \mathrm{mmHg}$. A firm, mobile, non-tender nodule approximately $2 \mathrm{~cm}$ in diameter was noted in the right lobe of the thyroid. The rest of the gland felt normal. There was no음 lymphadenopathy, nor was there a bruit or thrill. Eye signs of thyroid disease were absent. The rest of 3 the clinical examination was entirely normal.

$\mathrm{Her} \mathrm{Hb}$ and blood biochemistry were normal, $\frac{\delta}{3}$ apart from an elevated serum $T_{4}$ concentration of $235 \mu \mathrm{mol} / \mathrm{l}$ (normal range 50-150). Microsomal and은 thyroglobulin antibodies as well as thyroid stimu- $\frac{D}{8}$ lating immunoglobulin were not detected in the serum.

A chest X-ray with views of the thoracic inlet was reported as normal with no evidence of retrosternal extension of the thyroid.

A ${ }^{131}$ I scinitscan showed that nearly all of the tracer was concentrated in the region of the palpablese nodule, with suppressed activity in the rest of the gland (Fig. 1).

An ultrasound study showed a solid irregular mass ${ }^{\circ}$ in the right lobe of the thyroid. A smaller mass in the $\frac{\mathrm{O}}{\mathrm{D}}$ lower pole of the left lobe was also reported. 


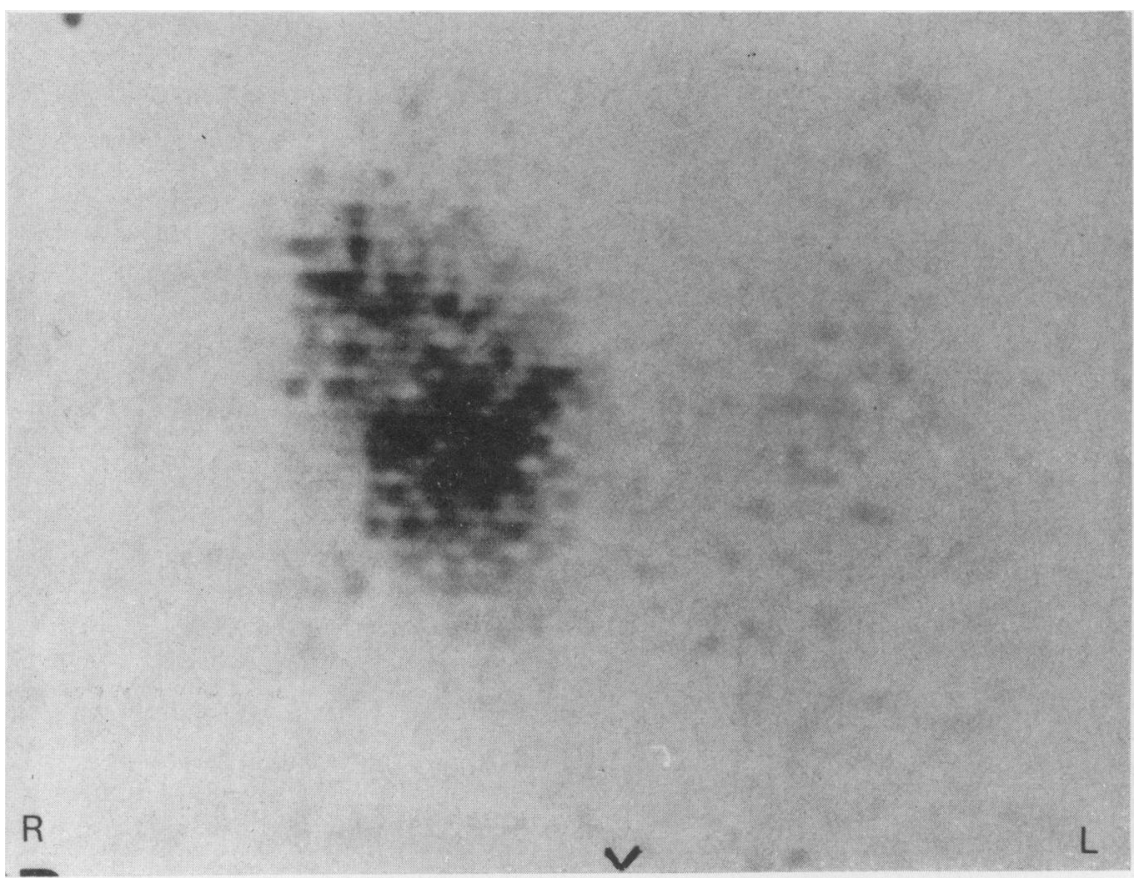

FIG. 1. ${ }^{131}$ I scintigraphy of thyroid showing 'hot' nodule.

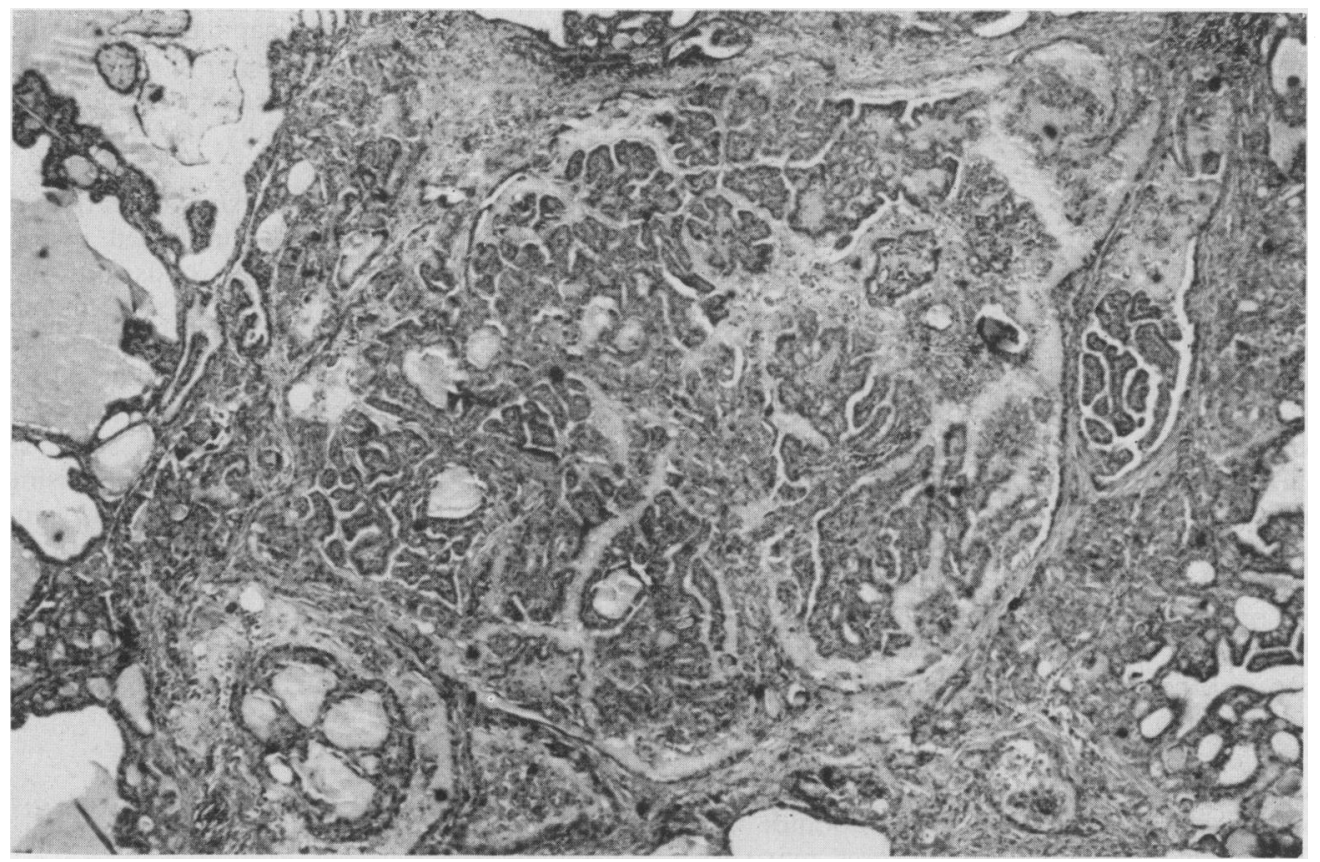

FIG. 2. Shows a well encapsulated nodule of the thyroid containing a papillary carcinoma $(\mathrm{HE}, \times 20)$. 


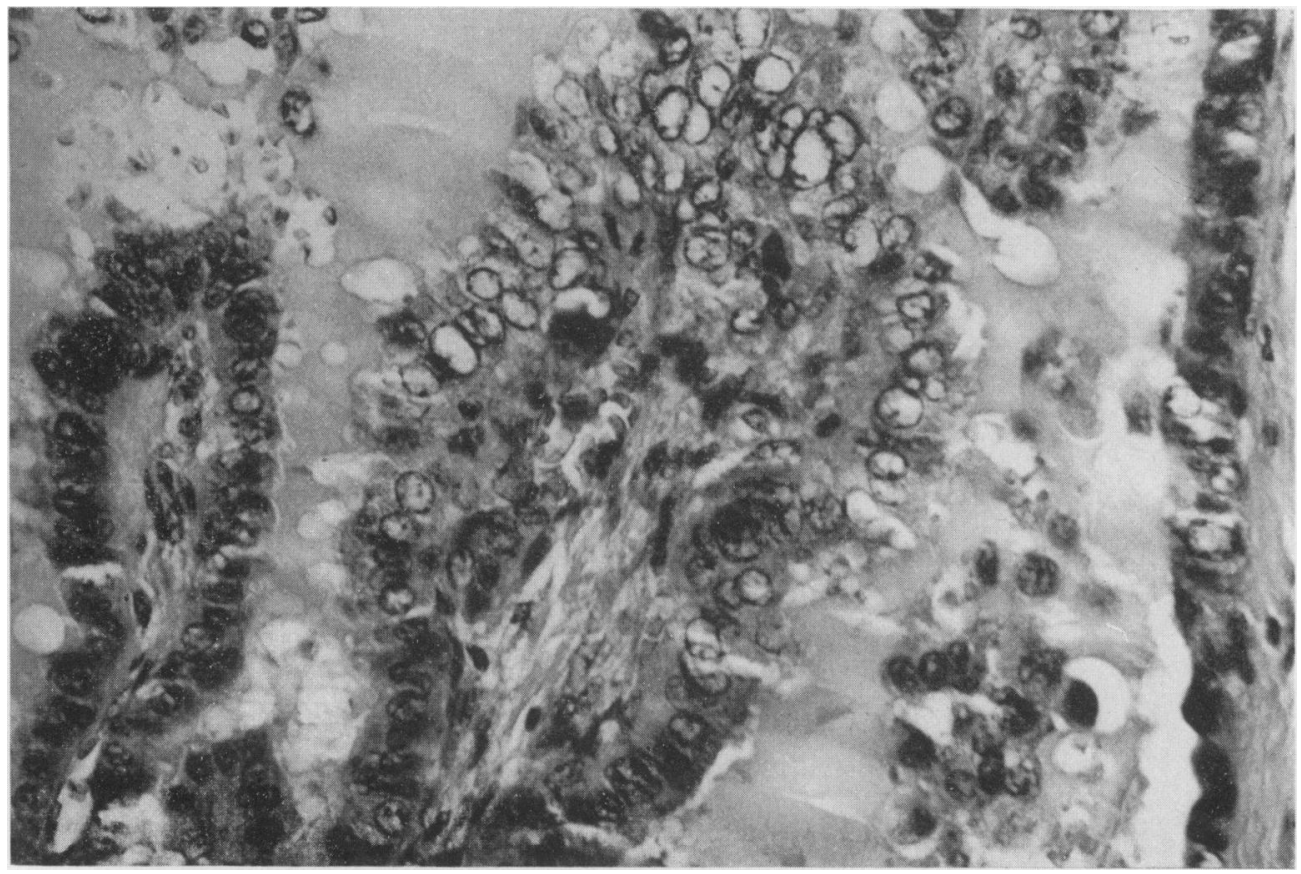

Fig. 3. Shows the tip of a papilla demonstrating chromatin abnormalities.

The patient was treated with antithyroid drugs for 4 weeks before surgery and the serum thyroxine concentration just before her operation was 165 $\mu \mathrm{mol} / \mathrm{l}$.

A partial thyroidectomy was performed in May 1979 when a nodule was found in the right lobe of the thyroid and diffuse enlargement of the left lobe was noted. No lymph nodes were involved. Both lobes of the gland were mobilized and removed, leaving a small remnant on either side of the trachea.

Histology of the resected thyroid (Fig. 2) showed a $2 \cdot 5-\mathrm{cm}$ diameter nodule made up of follicles lined by cuboidal epithelial cells which in areas showed papillary infoldings, within which the nuclei showed a regularly dispersed chromatin pattern (Fig. 3). The colloid of the follicles showed prominent marginal vesiculation. In the centre of the nodule was an area of papillary carcinoma approximately $0.3 \mathrm{~cm}$ in diameter. The tumour contained neoplastic papilli with fibrovascular cores, the cells of which had pale nuclei, and neoplastic follicular elements were also present.

Numerous other sections of the thyroid showed it to be tumour-free and partially suppressed.

\section{Discussion}

Autonomous functioning thyroid nodules, although benign in the vast majority of cases, may very rarely be malignant or, as in this case, harbour a malignancy. The extreme rarity of such an occu항ㅇㅇ rence is seen from review of the literature, which shows only 10 such cases. Histologically these carcinomas have been papillary in 8 instances (Lamberg et al., 1976), follicular in one (Ghose et al., $\unrhd$ 1971) and mixed in another (Sussman, Librik and $\vec{O}$ Clayton, 1968). Functionally, in 8 instances the 3 patients were euthyroid.

All of these tumours were small, less than one $\mathrm{cm}$. in diameter, and were all embedded in a hyper-음 functioning nodule (Molnar, Childs and Woolner, $\underline{3}$. 1958; Meadows, 1961). The present patient was found to have a papillary carcinoma in an autonomously functioning nodule. The carcinoma was indistinguishable from the rest of the hot nodule on scintigraphy but, on account of its small size, its 음 presence as a cold spot would, not surprisingly, be $>$ rather difficult to see as a separate entity in a hot nodule some 6-8 times as large. One possible N interpretation of these findings could be that the thyroid had developed an autonomous nodule in an $N$ area that, by chance, contained a papillary carci- $\mathbb{E}$ noma, rather than the whole nodule being a carcinoma.

\section{Acknowledgments}

The authors wish to express their sincere thanks to Professor I. Doniach for kindly reviewing the histology.

K.A.M. is in receipt of a Wellcome Research Fellowship. $\frac{\varrho}{\square}$ 


\section{References}

Bloise, W., Nicolau, W., Wajchenberg, B.L., Pieroni, R.R., Toledo, A.C., Martar, E. \& Cintra, A.B.U. (1963) Thyrotoxic crisis and electrolyte disturbances in a patient with functioning metastatic carcinoma of the thyroid: chromatographic and electrophoretic studies. Journal of Clinical Endocrinology, 23, 1096.

Ghose, M.K., Genuth, S.M., Abeliera, R.M., Friedman, S. \& LIDSKY, I. (1971) Functioning primary thyroid carcinoma and metastases producing hyperthyroidism. Journal of Clinical Endocrinology and Metabolism, 33, 639.

Hunt Jr, W.B., Crispell, K.R. \& McKee, J. (1960) Functioning metastatic carcinoma of the thyroid producing clinical hyperthyroidism. American Journal of Medicine, 28, 995.
Lamberg, B.A., Makinen, J. \& Murtom, A.A. (1976) Papillary thyroid carcinoma in a toxic adenoma. Nuclear Medicine, 15, 138.

Meadows, P.M. (1961) Scintillation scanning in the management of the clinically single thyroid nodule. Journal of the American Medical Association, 177, 229.

Molnar, G.D., Childs, D.S. \& Woolner, L.B. (1958) Histologic evidence of malignancy in a thyroid gland bearing a 'hot' nodule. Journal of Clinical Endocrinology and Metabolism, 18, 1132.

Sussman, L., Librik, L. \& Clayton, G.W. (1968) Hyperthyroidism attributable to a hyperfunctioning thyroid carcinoma. Journal of Pediatrics, 72, 208. 